\title{
Research Concerning the Efficiency of Aronia Melanocarpa for Pharmaceutical Purpose
}

\author{
Naliana Lupascu
}

Umf Carol Davila Bucharest, Faculty of Pharmacy, Bucharest, Romania

Emin Cadar

Umf Carol Davila Bucharest, Faculty of Pharmacy, Bucharest, Romania

Melat Cherim

Umf Carol Davila Bucharest, Faculty of Pharmacy, Bucharest, Romania

Cristina-Luiza Erimia

Ovidius University of Constanta, Faculty of Pharmacy, Constanta, Romania

Rodica Sîrbu

Ovidius University of Constanta, Faculty of Pharmacy, Constanta, Romania

\begin{abstract}
The major impact of many types of disease on the human body have generated medical research orientation toward biotechnology identification and extraction of active principles from natural resources. The social problem to improve the health of the population, to maintain social balance of a healthy society oriented medicalpharmaceutical research for the use of other sources of pharmaceuticals from natural sources and not synthetic chemistry. On this line of work is also included the research wich orientates pharmaceutical medical studies by using new sources of bioactive compounds such as: anthocyanes, flavonoids, phenolic acids, chlorogenic acid, tannins, vitamin P,C, B2, B6 from the shrub Aronia Melanocarpa. Besides these compounds are also found in the fruits different cyanidin glycosides: 3-galactoside, 3-glucoside, 3-arabinoside and 3-xyloside. The rich content in bioactive forms makes possible the use in treating certain diseases by using internal use in household. For internal use are used by diabetics having hypoglycemic effect, astringent properties and very strong diuretics, they are cardiac tonic, regulates blood pressure and blood glucose, treatment of varicose veins and hemorrhoids, it has a good hepatoprotective effect due to its high iodine content, are effective in hyperthyroidism and can be consumed by sufferers of Alzheimer's disease and relieving symptoms slowig the aging processes.
\end{abstract}

Keywords: antioxidant activity, anthocyanes, flavonoids, phenolic acids, chlorogenic acid, tannins, vitamin P, C, B2, B6

\section{Introduction}

Of all the least studied species in our country and with strong antioxidant effect our attention was drawn to Aronia melanocarpa, multiyear shrub, native of North America but brought into the country a few years ago. Calling itself also the "miracle fruit" in our country is cultivated mainly for ornamental reasons, but in other countries like America, Serbia, Russia, Bulgaria, Poland, Germany it is part of tree programs. In addition to decorative purposes, there are industrial plantations of Aronia because the fruits are edible, and the high content of antioxidants ( 15 times more than blueberries), resveratrol and vitamins may be a solid reason for establishing this culture in Romania, especially that the plant does not require heat, resistant to cold weather and frost, diseases or pests. There are shrubs with wonderful fruit crops in: Alexandria (Teleorman), Satu Mare, Craiova. The purpose of this paper is to study and characterize the species of Aronia Melanocarpa for use as feedstock for active principles of therapeutic interest. 


\section{Medicinal Herbs}

In Dobrogea the art of healing diseases was greatly expanded along monasteries, where monks were used to gathering and processing medicinal plants. In the same time in villages there were numerous healers to call on, if necessary, the majority of the population. By communion with nature, native people always loved plants and have used the gifts offered by them with great skill and wisdom. In practice folk weeds were gleaned during the optimal harvest time, dried and prepared as concoctions aqueous extract by soaking in an acid environment (wine, vinegar), alcohol extraction (brandy, liqueur) in oil or by preparation of some based ointments, cream, butter or sheep fat.. [1]

\section{Aronia Melanocarpa}

Aronia Melanocarpa, Family Rosaceae is grouped in Subfamily Maloideae with Pyrus, Malus, Amelanchier, Sorbus and Photinia and is included by some authors in Pyrus or Photinia. There are reports with (Scorbus spp) [2, 3] The genus Aronia (Rosaceae family, Maloideae subfamily) includes two species of deciduous North American shrubs: A. melanocarpa (Michx.) Ell., known as black chokeberry, and Aronia arbutifolia (L.) Pers. (red chokeberry) plus a purple chokeberry whose origin is a natural hybrid of the two. $[4,5]$

Red chokeberry, Aronia arbutifolia (Photinia pyrifolia), grows to 2-4 $m$ tall, rarely up to $6 \mathrm{~m}$ and 1-2 $\mathrm{m}$ wide. Leaves are $5-8 \mathrm{~cm}$ wide and densely pubescent on the underside. The flowers are white or pale pink, $1 \mathrm{~cm}$ wide, with glandular sepals. The fruit is red, 4-10 $\mathrm{mm}$ wide, persisting into winter.

Black chokeberry, Aronia melanocarpa (Photinia melanocarpa) $[5,6]$ tends to be smaller, rarely exceeding $1 \mathrm{~m}$ tall and 3 $\mathrm{m}$ wide, and spreads readily by root sprouts. The leaves are smaller, not more than $6 \mathrm{~cm}$ wide, with terminal glands on leaf teeth and a glabrous underside. The flowers are white, $1.5 \mathrm{~cm}$ wide, with glabrous sepals. The fruit is black, 6-9 $\mathrm{mm}$ wide, not persisting into winter.

Purple chokeberry, Aronia prunifolia (Photinia floribunda) $[5,7]$ apparently originated as a hybrid of the black and red chokeberries but might be more accurately considered a distinct species than a hybrid [4,5] (see also nothospecies). Leaves are moderately pubescent on the underside. Few to no glands are present on the sepal surface. The fruit is dark purple to black, $7-10 \mathrm{~mm}$ in width, not persisting into winter. There are purple chokeberry populations which seem to be selfsustaining independent of the two parent species [4]. The range of the purple chokeberry is roughly that of the black chokeberry.

\section{Pharmacologically Constituients}

\section{Anthocyanins in aronia melanocarpa}

Much of the interest in Aronia Melanocarpa fruit is focused on its anthocyanin content. The juice from Aronia melanocarpa berries is a source of phenolic compounds with antioxidant properties: procyanidins, anthocyanins, (-)-epicatechin, chlorogenic acid, neochlorogenic acid. [8]

In chokeberry fruits, anthocyanins constitute the second largest group of phenolic compounds $[4,27]$. The anthocyanins in A. melanocarpa are mainly a mixture of four cyanidin glycosides: 3-galactoside, 3-glucoside, 3-arabinoside and 3-xyloside, of which cyanidin 3-galactoside is the main one (Figure 1) $[9,10]$.

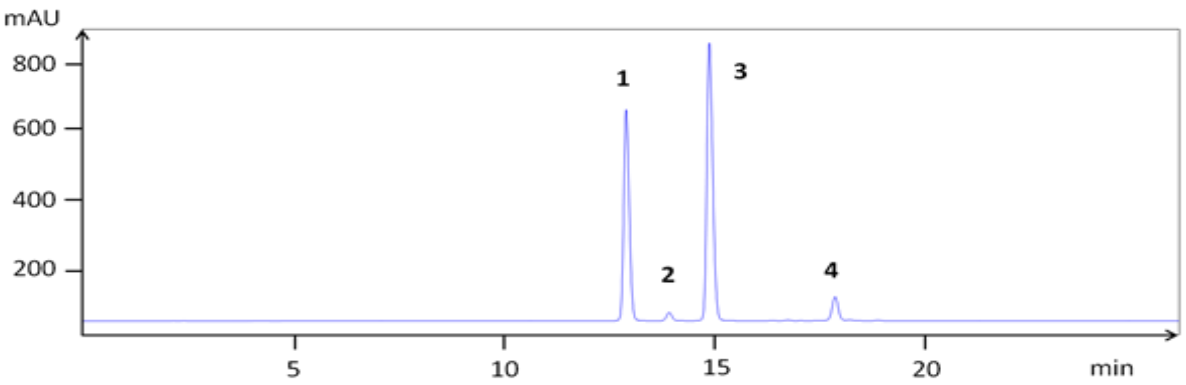

Figure 1. High-performance liquid chromatography (HPLC) chromatogram of the isolated anthocyanins: cyanidin 3galactoside (1), cyanidin 3-glucoside (2), cyanidin 3-arabinoside (3) and cyanidin 3-xyloside (4). [9, 10]. 
Other flavonoid compounds were also identified in both fruits and flowers of A. Melanocarpa.<smiles></smiles>

$\begin{array}{llll}\text { cyanidin-3-O-galactoside } & \mathrm{R}_{1}=\text { gal } & \mathrm{R}_{2}=\mathrm{OH} & \mathrm{R}_{3}=\mathrm{OH} \\ \text { cyanidin-3-O-glucoside } & \mathrm{R}_{1}=\text { glc } & \mathrm{R}_{2}=\mathrm{OH} & \mathrm{R}_{3}=\mathrm{OH} \\ \text { cyanidin-3-O-xyloside } & \mathrm{R}_{1}=\text { xyl } & \mathrm{R}_{2}=\mathrm{OH} & \mathrm{R}_{3}=\mathrm{OH} \\ \text { cyanidin-3-O-arabinoside } & \mathrm{R}_{1}=\text { ara } & \mathrm{R}_{2}=\mathrm{OH} & \mathrm{R}_{3}=\mathrm{OH} \\ \text { pelargonidin-3-O-arabinoside } & \mathrm{R}_{1}=\text { ara } & \mathrm{R}_{2}=\mathrm{H} & \mathrm{R}_{3}=\mathrm{OH} \\ \text { pelargonidin-3-O-galactoside } & \mathrm{R}_{1}=\text { gal } & \mathrm{R}_{2}=\mathrm{H} & \mathrm{R}_{3}=\mathrm{OH}\end{array}$

Fig. 2 Chemical structures of anthocyanins present in A. melanocarpa. [11]

Five flavonol-quercetin derivatives - 3-vicianoside (6"-0-b- arabinosyl-b-glucoside), 3-robinobioside (6"-a-rhamnosyl- bgalactoside), 3-rutinoside (6"-a-rhamnosyl-b glucoside), 3-b-galactoside, and 3-b-glucoside - were also identified in flower umbels of A. melanocarpa (Fig.2) [10,11]<smiles>O=c1c(O)c(-c2ccc(O)c(O)c2)oc2cc(O)cc(O)c12</smiles>

$$
\begin{aligned}
& \mathrm{R}=6 \text { " }-\mathrm{O}-\beta \text {-arabinosyl }-\beta \text {-glucoside }=\text { Quercetin 3-vicianoside } \\
& R=6 \text { "- } \alpha \text {-ramnosyl- } \beta \text {-galactoside } \quad=\text { Quercetin 3-robinobioside } \\
& R=6 \text { " }-\alpha \text {-ramnosyl- } \beta \text {-glucoside } \quad=\text { Quercetin 3-rutinoside } \\
& \mathrm{R}=\beta \text {-galactoside } \quad \text { = Quercetin 3-galactoside } \\
& R=\beta \text {-glucoside } \quad \text { = Quercetin 3-glucoside }
\end{aligned}
$$<smiles>O=C1CC(c2ccc(O)c(O)c2)Oc2cc(O[C@@H]3O[C@H](C(=O)O)[C@H](O)[C@H](O)[C@H]3O)cc(O)c21</smiles>

Eriodictyol 7-glucuronide

Fig.3. Chemical structures of quercetin glycosides and eriodictyol glucuronide present in A. melanocarpa.

\section{Pharmacological Activity}

\section{a) Antidiabetic activity}

Aronia melanocarpa fruit juice (AMFJ) is rich in phenolic antioxidants, especially flavonoids from the anthocyanin subclass.

In a study was researched the influence of AMFJ on plasma glucose and lipids in diabetic rats. Diabetes was induced by an intraperitoneal injection of streptozotocin $(50 \mathrm{mg} / \mathrm{kg})$. AMFJ was applied by gavage at doses of 10 and $20 \mathrm{ml} / \mathrm{kg}$ for 6 weeks to normal and diabetic rats. Streptozotocin caused a significant elevation of plasma glucose by $141 \%$ and of plasma triglycerides (TG) by $64 \%$ in comparison with normal control rats and induced statistically insignificant elevations of total cholesterol and LDL-cholesterol and a reduction of HDL-cholesterol.

Tabele 1. Chemical composition in Aronia Melanocarpa [12] 


\begin{tabular}{|l|l|l|l|}
\hline & FRUITS & FRESH JUICE & PASTEURIZED JUICE \\
\hline Constituents & $3.3-3.7$ & 3.6 & 3.3 \\
\hline $\mathrm{pH}$ & 41 & 41 & 40 \\
\hline Glucose g/L & 40 & 38 & 37 \\
\hline Fructozse g/L & 13.1 & 9.0 & 11.1 \\
\hline Organic acids & 2.1 & 0.500 & 0.247 \\
\hline $\begin{array}{l}\text { Malic Acid } \\
\text { g/Kg }\end{array}$ & \multicolumn{3}{|l|}{} \\
\hline Citric Acid g/Kg & \multicolumn{3}{|l|}{} \\
\hline Minerals & 2180 & 1969 \\
\hline K mg/L & 2850 & 150 & 185 \\
\hline Ca mg/L & 322 & 140 & 160 \\
\hline Mg mg/L & 162 & 4 & 0.4 \\
\hline Fe mg/L & 9.3 & 1.3 & 0.6 \\
\hline Za & 1.47 & \\
\hline Vitamins & $180 \mathrm{mg} / \mathrm{Kg}$ & $500 \mathrm{mg} / \mathrm{L}$ & NOT DETECTED \\
\hline B1 Vitamin & $200 \mathrm{mg} / \mathrm{Kg}$ & $600 \mathrm{mg} / \mathrm{L}$ & NOT DETECTED \\
\hline B2 Vitamin & $280 \mathrm{mg} / \mathrm{Kg}$ & $550 \mathrm{mg} / \mathrm{L}$ & NOT DETECTED \\
\hline B6 Vitamin & $2790 \mathrm{mg} / \mathrm{Kg}$ & $2200 \mathrm{mg} / \mathrm{L}$ & NOT DETECTED \\
\hline Pantotenic Acid & $137 \mathrm{mg} / \mathrm{kg}$ & $200 \mathrm{mg} / \mathrm{L}$ & NOT DETECTED \\
\hline C Vitamin &
\end{tabular}

Applied to normal rats, AMFJ did not influence plasma glucose and lipid levels. Applied to diabetic rats, AMFJ (10 and 20 $\mathrm{ml} / \mathrm{kg}$ ) significantly reduced plasma glucose by $44 \%$ and $42 \%$ and TG by $35 \%$ and $39 \%$, respectively, to levels that did not significantly differ from those of the normal control rats and counteracted the influence of streptozotocin on total cholesterol, LDL-cholesterol and HDL-cholesterol. In conclusion, AMFJ significantly decreased the streptozotocin-induced abnormalities in blood glucose and TG in diabetic rats and might be useful in prevention and control of diabetes mellitus and diabetes-associated complications.

The antidiabetic activity of A. melanocarpa juice was demonstrated in patients with dia- betes mellitus. It was shown that daily ingestion of $200 \mathrm{~mL}$ of sugar-free black chokeberry juice over a 3-month period resulted in substantially lower fasting blood glucose levels in patients with non-insulin-dependent diabetes compared to the control group. The observed results indicate that supplementation of the diet with Aronia juice may exert beneficial supporting effects in diabetic patients. [13]

\section{b) Anti-inflammatory effects, antibacterial and antiviral activity}

Valcheva (2006) studied intensively anti-inflammatory effects and bacteriostatic activity of Aronia juice. Her investigation has demonstrated a remarkable hepatoprotective, a very good gastro protective and a pronounced anti-inflammatory effect of Aronia melanocarpa fruit juice in rats as well as a bacteriostatic activity in vitro against Staphylococcus aureus and Escherichia coli and an antiviral activity against type A influenza virus. The properties of Aronia were attributed to two constituents, ellagic acid and myricetin. In an in vivo therapeutic mouse model, Aronia, ellagic acid, and myricetin protected mice against lethal challenge. Based on these results, we suggest that Aronia is a valuable source for antiviral agents and that ellagic acid and myricetin have potential as influenza therapeutics.[14]

Another research was made by Ohgami K, et all. (2005). This study shows the anti-inflammatory power of Aronia: "the antiinflammatory effect of $100 \mathrm{mg}$ Aronia extract was as strong as that of $10 \mathrm{mg}$ prednisolone", "The anti-inflammatory action of Aronia extract was stronger than that of either quercetin or anthocyanin administered alone." [15]

The anti-inflammatory effects of the anthocyane flavonoids in the natural juice from Aronia melanocarpa and of rutinmagnesium complex, the water-soluble derivative of rutin were studied in comparison with rutin. Two experimental models of inflammation were used. Inflammation of rat hind paw was induced either by $0.5 \%$ solution of histamine or by $0.01 \%$ solution of serotonin. The results showed that the anthocyane flavonoids from the natural juice of Aronia melanocarpa exerted more pronounced effects as compared to rutin in both models of inflammation. 


\section{c) Antioxidant activity}

Aronia melanocarpa contain particularly high amounts of procyanidins, anthocyanins, and phenolic acids but the highest total phenolics and anthocyanin contents were found in chokeberry pomace with the values of $63.1 \mathrm{~g}$ per kg expressed as gallic acid equivalents, and $4.5 \mathrm{~g}$ per kg expressed as cyanidin-3-glucoside equivalents. [16]

The extract from A. melanocarpa $(5-50 \mu \mathrm{g} / \mathrm{mL})$ significantly inhibited platelet protein carbonylation (measured by ELISA method) and thiol oxidation estimated with 5,5'-dithio-bis(2-nitro-benzoic acid) (DTNB) induced by peroxynitrite (0.1 mM) (IC50 - $35 \mu \mathrm{g} / \mathrm{mL}$ for protein carbonylation, and IC50 - 33 $\mathrm{gg} / \mathrm{mL}$ for protein thiol oxidation). The extract from A. melanocarpa seems to be also useful as an antioxidant in patients with breast cancer.[17]

The extract from A. melanocarpa $(5-50 \mu \mathrm{g} / \mathrm{mL})$ can plau an important role as components of human diet in prevention of cardiovascular or inflammatory diseases, where blood platelets are involved. [15]

Also, A. melanocarpa berries exert significant anti-platelet effects ex vivo.[18]

\section{d) Anxiolytic activity}

Anxiolytic activity has been demonstrated by Valcheva (2009). She investigated the effects of AMFJ ( 5 and $10 \mathrm{~mL} / \mathrm{kg}$ ) on anxiety using the social interaction test, on locomotor activity in the open field test and on working memory in the object recognition test in rats. AMFJ showed an anxiolyticlike effect which was demonstrated by a dose-dependent increase in the time of active social contacts between the test partners. The effects of both AMFJ doses were comparable to the effect of diazepam (1 mg/kg). AMFJ neither changed significantly horizontal and vertical locomotor activity, nor did it adversely affect working memory [19]

\section{e) Anticancer activity}

In breast cancer patients (before and during anti-cancer therapy) oxidative/nitrative damage to various molecules is observed.

A. melanocarpa berries significantly reduced, in in vitro system, the oxidative/nitrative stress and hemostasis changes in plasma from breast cancerpatients, after surgery and different phases of chemotherapy.[20]

In another study in acute lymphoblastic leukemia Aronia melanocarpa juice (AMJ) containing $7.15 \mathrm{~g} / \mathrm{L}$ of polyphenols inhibited cell proliferation, which was associated with cell cycle arrest in G2/M phase, and caused the induction of apoptosis. AMJ significantly increased the formation of reactive oxygen species (ROS), decreased the mitochondrial membrane potential and caused the release of cytochrome $\mathrm{c}$ into the cytoplasm. AMJ treatment also induced apoptosis of different human lymphoblastic leukemia cells (HSB-2, Molt-4 and CCRF-CEM). In addition, AMJ exerted a strong pro-apoptotic effect in human primary lymphoblastic leukemia cells but not in human normal primary $T$ lymphocytes. AMJ has chemotherapeutic properties against acute lymphoblastic leukemia by selectively targeting lymphoblast derived tumor cells. [23]

A. melanocarpa juice was shown to strongly inhibit sulfoconjugation of $17 \mathrm{~b}$-estradiol in Caco-2 cells and also to exhibit an inhibitory effect on cytosolic sulfotransferase, the enzyme involved in estrogen deactivation, from human carcinoma cells in vitro. These results indicate that black chokeberry extracts might influence the growth of some breast and colon cancers through sulfotransferase inhibition, and therefore alter estrogen availability to their receptors. [20]

The effect of semipurified anthocyanin-rich was investigated extract from fruits of Aronia meloncarpa, on normal colon and colon cancer cell lines. A 24-h exposure to $50 \mu \mathrm{g}$ monomeric anthocyanin $/ \mathrm{ml}$ of Aronia extract resulted in $60 \%$ growth inhibition of human HT-29 colon cancer cells. The treated cells showed a blockage at G1/G0 and G2/M phases of the cell cy- cle. The cell cycle arrest coincided with an increased expression of the p21WAF1 and p27KIP1 genes and decreased expression of cyclin A and B genes.

Prolonged exposure to the extract resulted in no further change in the cell number, indicating a cytostatic inhibition of cell growth. NCM460 normal colon cells demonstrated $<10 \%$ growth inhibition at the highest concentration of $50 \mu \mathrm{g} / \mathrm{ml}$ extract. A $35 \%$ decrease in the cyclooxygenase-2 gene expression was observed within $24 \mathrm{~h}$ of exposure of HT-29 cells but did not translate into de- creased protein levels or protein activity. [21] 


\section{Conclusions}

- Modern pharmacological research presents A. melanocarpa as a plant with numerous Health - promoting activities. [11].

- $\quad$ Aronia melanocarpa contain particularly high amounts of procyanidins, anthocyanins, and phenolic acids. These antioxidants reduce the oxidative damage of human cells that can lead to cancer, heart disease, diabetes, hypertension, hypercholesterolemia. The black chokeberry may be used in the treatment and prevention of numerous civilization diseases. [22]

- The fruit of Aronia has proven to be one of nature's most powerful antioxidants, rich in nutrients and vitamins, offering extraordinary benefits to the ones that want to improve their health through healthy eating habits. Today Aronia fruit due to antioxidant phenols, are demanded on the world market as a quality dietary product, welcomed in daily food ration for strengthening the body and promote healthy lifestyles.

\section{References}

[1] www. Scribe.com;

[2] Kim JI, Lee I, Lee S, Hwang MW, Bae JY, Heo J, Kim D, Han SZ, Park MS "Aronia melanocarpa and its components demonstrate antiviral activity against influenza viruses" iochem Biophys Res Commun. 2013 Oct 11; 440(1):14-9;

[3] Robert W. Scott, Robert M. Skirvin - Black Chokeberry (Aronia Melanocarpa Michx): A semi- Edible Fruit with No Pests, Journal of the American Pomological Society 61 (3) : 135-137, 2007;

[4] Alan S. Weakley. "Flora of the Carolinas, Virginia, and Georgia, and Surrounding Areas", 2008;

[5] Zielińska M, Gryglicka H., Kamil K. Hozyasz - Chokeberry "Antioxidant (oxidative damage, cancer, heart disease, diabetes, hypertention, hypercholesterolemia, treatment, prevention)"- clinical perspectives Pediatria Polska 88(5), Sept.-Oct. 2013, pp. 452-458

[6] K.R. Robertson \& Phipps "Photinia floribunda". United States Departament of Agriculture, Natural Resources Conservation Service.

[7] Malik M, Zhao C W, Schoene N, Guisti M M, Moyer M P, Magnuson B A "Anthocyanin-rich extract from Aronia melanocarpa E. induces a cell cycle block in colon cancer but not normal colonic cells" Nutr Cancer 2003; 46: 186-96;

[8] Eliza Oprea, Bogdan Nicolae Manolescu, lleana Cornelia Fărcășanu, Paulina Mladin, Dana Mihele, "Studies concerning antioxidant and hypoglycaemic activity of aronia melanocarpa fruits", Farmacia 2014, vol 62, 2, pag. 254;

[9] Bräunlich M., Slimestad R., Wangensteen H, Brede C., Karl E. Malterud and Hilde Barsett "Extracts, Anthocyanins and Procyanidins from Aronia melanocarpa as Radical Scavengers and Enzyme Inhibitors " Nutrients, 2013, 5, 663-678;

[10] Slimestad,R.;Torskangerpoll,K.;Nateland,H.S.;Johannessen,T.;Giske,N.H.Flavonoids from black chokeberries, Aronia melanocarpa. J. Food Comp. Anal. 2005, 18, 61-68.;

[11] Adam Kokotkiewicz, Zbigniew Jaremicz, and Maria Luczkiewicz "Aronia Plants: A Review of Traditional Use, Biological Activities, and Perspectives for Modern Medicine" Journal Of Medicinal Food isepe.J Med Food 13 (2) 2010, 255-269;

[12] Sabine E. Kulling, Harshadai M. Rawel, "Chokeberry (Aronia melanocarpa) - A Review on the Characteristic Components and Potential Health Effects" Planta Med 2008; 74: 1625-1634;

[13] Simeonov SB, Botushanov NP, Karahanian EB, Pavlova MB, Husianitis HK, Troev DM: Effects of Aronia melanocarpa j 2002;44:20-23; uice as part of the dietary regimen in patients with diabetes mellitus. Folia Med (Plovdiv) 
[14] JI, Lee I, Lee S, Hwang MW, Bae JY, Heo J, Kim D, Han SZ, Park MS "Aronia melanocarpa and its components demonstrate antiviral activity against influenza viruses" iochem Biophys Res Commun. 2013 Oct $11 ; 440(1): 14-9$;

[15] Ohgami K, llieva I, Shiratori K, Koyama Y, Jin XH, Yoshida K, Kase S, Kitaichi N, Suzuki Y, Tanaka T, Ohno S."Anti-inflammatory effects of aronia extract on rat endotoxin-induced uveitis" Invest Ophthalmol Vis Sci. 2005 Jan;46(1):275-81;

[16] Rajchl, A., Č́žková, H., Kapci, B., Voldřich, M., Capanoglu, E., Neradová, E. "Investigating the antioxidant potential of chokeberry (Aronia melanocarpa) products" Journal of Food and Nutrition Research 52(4), 07/2013;

[17] Olas B, Wachowicz B, Tomczak A, Erler J, Stochmal A, Oleszek W "Comparative anti-platelet and antioxidant properties of polyphenol-rich extracts from: berries of Aronia melanocarpa, seeds of grape and bark of Yucca schidigera in vitro Platelets" 2008; 19: 70-77;

[18] Ryszawa, A. Kawczynska-Drozdz, J. Pryjma, M. Czesnikiewicz-Guzik, T. Adamek-Guzik, M. Naruszewicz, R. Korbut, T. J. Guzik "Effects of novel plant antioxidants on platelet superoxide production and aggregation in atherosclerosis" Journal of Physiology and Pharmacology 57(4), 12/2006;

[19] Valcheva-Kuzmanova, S., Zhelyazkova-Savova, M. "Anxiolytic-like effect of Aronia melanocarpa fruit juice in rats Methods Find Exp Clin Pharmacol 2009, 31(10): 651. DOI: 10.1358/mf.2009.31.10.1423884;

[20] Kędzierska M, Malinowska J, Kontek B, Kołodziejczyk-Czepas J, Czernek U, Potemski P, Piekarski J, Jeziorski A, Olas B. "Chemotherapy modulates the biological activity of breast cancer patients plasma: the protective properties of black chokeberry extract" Food Chem Toxicol. 2013 Mar; 53: 126-32. doi: 10.1016/j.fct.2012.11.042. Epub 2012 Dec 5;

[21] Malik M, Zhao C W, Schoene N, Guisti M M, Moyer M P, Magnuson B A "Anthocyanin-rich extract from Aronia melanocarpa E. induces a cell cycle block in colon cancer but not normal colonic cells" Nutr Cancer 2003; 46: 186-96;

[22] Zielińska M, Gryglicka H., Kamil K. Hozyasz - Chokeberry "Antioxidant (oxidative damage, cancer, heart disease, diabetes, hypertention, hypercholesterolemia, treatment, prevention)"-clinical perspectives Pediatria Polska 88(5), Sept.-Oct. 2013, pp. 452-458 